\title{
Pott's puffy tumor: as a very rare and unpredicted complication of ipsilateral pan sinusitis - case presentation and review of articles*
}

\author{
Khaled Mohamed Bofares ${ }^{1}$, Zalfi Adim Haqqar², Iman Musbah Ali ${ }^{3}$ \\ Omar Almoukhtar University, Elbyda, Libya \\ 2AL-thawra teaching central hospital, AL-Beyda city- Libya \\ AL-thawra teaching central hospital, AL-Beyda city-Libya
}

Rhinology Online, Vol 4: 181 - 184, 2021

http://doi.org/10.4193/RHINOL/21.036

*Received for publication:

July 31,2021

Accepted: August 30, 2021

Published: September 6, 2021

\begin{abstract}
Pott's puffy tumor is considered as a rare clinical entity. It is developed as a rare complication of frontal sinusitis. In addition, the trauma to the frontal area is another suggested cause. The Pott's puffy tumor is presented as a forehead swelling due to sub-periosteal collection. Although, the Pott's puffy tumor is a rare condition but at the same time, it can be serious because it may lead to life threatening complications namely, extradural abscess, subdural abscess, meningitis, encephalitis, and brain abscess. Thus, the Pott's puffy tumor is classified as a very significant surgical emergency.
\end{abstract}

Key words: Pott's puffy tumor, frontal sinusitis rare complications, rhinosinusitis rare complications

\section{Introduction}

Pott's Puffy tumor is a rare clinical entity characterized by subperiosteal abscess associated with osteomyelitis. It is usually seen as a complication of frontal sinusitis or trauma to the frontal region predominantly in the adolescent age group ${ }^{(1-3)}$. Pott's puffy tumor requires rapid medical and surgical intervention to prevent complications that increase morbidity and mortality. Pott's Puffy tumor can be associated with serious complications as cortical vein thrombosis, epidural abscess, subdural empyema, and brain abscess ${ }^{(1-5)}$. The cause of vein thrombosis is explained by venous drainage of the frontal sinus, which occurs through diplopic veins, which communicate with the dural venous plexus; septic thrombi can potentially evolve from foci within the frontal sinus and propagate through this venous system ${ }^{(1-7)}$. These infections are often poly-microbial, with Streptococci, Staphylococci, and anaerobic bacteria, as they favor lower oxygen concentrations ${ }^{(1-7)}$. Since the advent of antibiotics, Pott's puffy tumor has become rare to the point of almost being forgotten and unpredicted.

\section{Case presentation}

A seventeen years old male Libyan patient presented at ENT
OPD, AL-thawra teaching central hospital, AL-Beyda city, Libya as a case of forehead swelling ten days of duration before the presentation. The swelling was associated with fever, generalized malaise and fatigability. There was history suggestive of upper respiratory tract infection accompanied with mucopurulent rhinorrhea, persistent nasal obstruction at left side around two weeks prior to the onset of the swelling. There was no history suggestive of a local trauma. The patient is a known case of chronic allergic rhinitis. Apart of the smoking (half packet per day) there was no any other significant history. On examination, generally the patient was looking sick, tired and mildly dehydrated. The body temperature was $38 \mathrm{C}^{\circ}$. The local examination revealed the presence of forehead swelling involving more the left side with regional reactive edema extending up to left periorbital region. The swelling was spherical in shape, around $3 \mathrm{~cm} \times 2.5 \mathrm{~cm}$ in size. The skin over the swelling did not show significant changes. On palpation of swelling, there was mild tenderness over the swelling with palpable bony defect of diameter around $0.5 \mathrm{~cm}$ at the corresponding cranial bone and there was clear fluctuation over the swelling. The endoscopic examination of the nose showed signs of nasal mucosal congestion with significant amount of purulent discharge at 


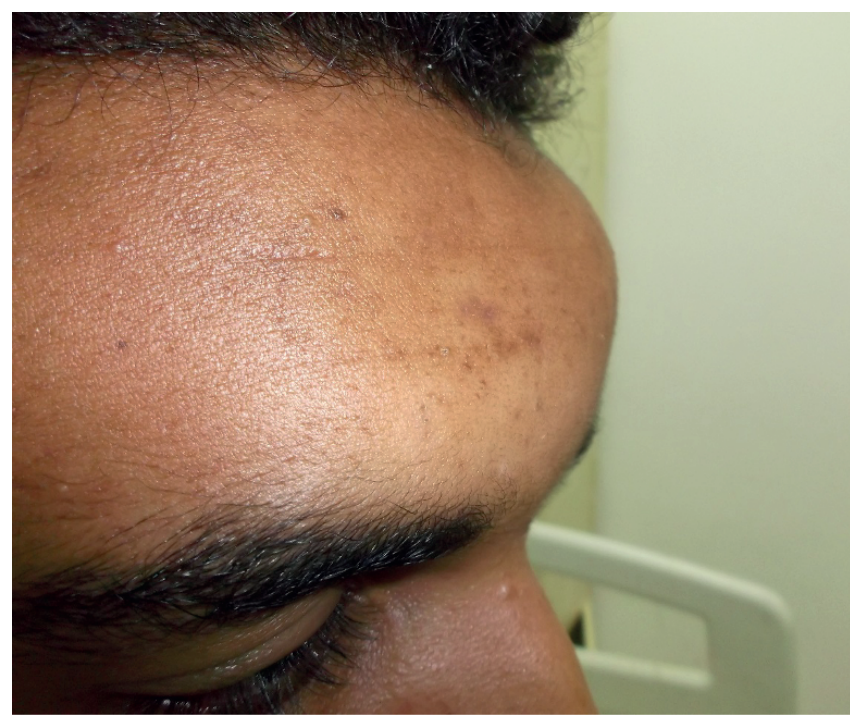

Figure 1. Clinical demonstration of Pott's puffy tumor.

the level of left middle meatus. The patient was investigated by blood tests as well as imaging evaluation in form of complete blood picture, erythrocyte sedimentation rate (ESR) and CT scan coronal, axial as well as sagittal views. The investigations showed significant leukocytosis $\left(16,000 / \mathrm{mm}^{3}\right)$, ESR was $20 \mathrm{~mm} / \mathrm{hr}$, and CT scan images revealed evidences of sub periosteal abscess of the cranial bone just above the left frontal sinus with evidences of left pan sinusitis without any evidences of intracranial involvement. By this moment, the patient was diagnosed as left pan sinusitis complicated by sub periosteal abscess of corresponding frontal cranial bone (Pott's puffy tumor). Thus, the case was considered as top surgical emergency and furtherly, the patient prepared for urgent surgical intervention which was done as left full house functional endoscopic sinus surgery, i.e.: in form of left anterior ethmoidectomy, left posterior ethmoidectomy, left sphenoidotomy, left frontostomy (Draf-I), as well as left middle meatal antrostomy. The intra-operative findings were revealed evidences of purulent secretions discharging at middle meatus and filling the left maxillary antrum, left ethmoidal air cells as well as left frontal sinus. There was evidences of granulomatous acute inflammatory changes involving the sino-nasal mucosa with high bleeding tendency. The ethmoid bone was fragile and easy to be exenterated and removed. In addition, the aspiration of the sub periosteal collected pus was done and resulting in the extraction of around $10 \mathrm{~cm}$ thick pus, which sent for culture and sensitivity. In accordance, the patient was kept at the department on parenteral antibiotics in form of ceftriaxone 1 gr every twelve hours, Augmentin 1,2gr every eight hours, and metronidazole 500mg every eight hours for twelve days, in addition to orally administrated antihistamines, analgesics, as well as local nasal douching, frequent nasal normal saline irrigation and suction. In addition, the patient was locally at site of abscess dressed daily for five days with tight- compressive bandage dressing to reduce the residual space and prevent the re-collection. After twelve days, the patient was discharged in good conditions on orally administrated Cefixime $400 \mathrm{mg}$ once a day for five days, Augmentin 1gr every twelve hours for five days, and metronidazole $500 \mathrm{mg}$ every eight hours for five days too, in addition to oral antihistamine as well as local nasal douching with hypertonic sea water spray.

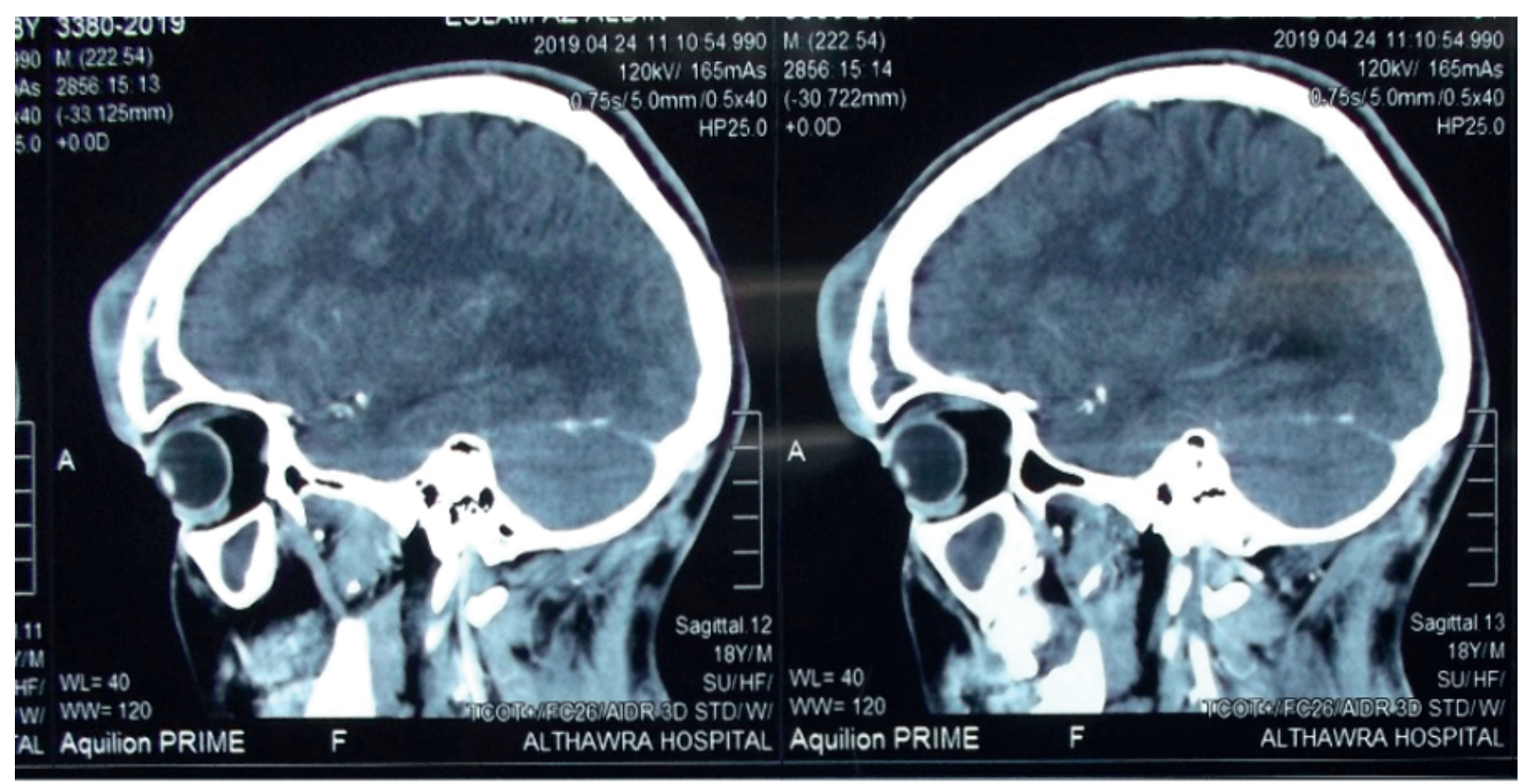

Figure 2. Sagittal CT- sections demonstrate the sub-periosteal abscess collection. 


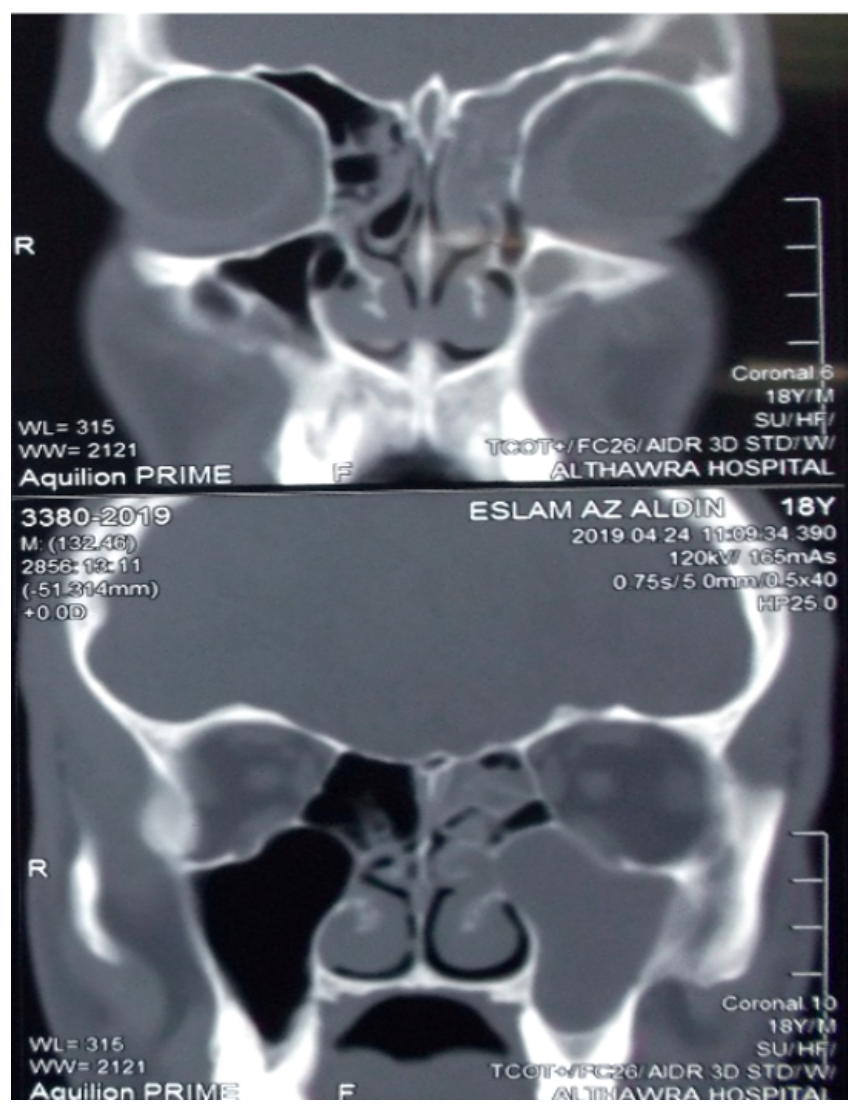

Figure 3. Coronal CT- sections demonstrate the left pansinusits.

By the follow up sessions, first after one week, second after four weeks, and the third after eight weeks, the patient proved with complete local healing including the site of collected sub-periosteal abscess and 4- no any subsequent aesthetic changes at the area of frontal region.

\section{Discussion and review of literature}

Pott's puffy tumor is a name describing a lesion in form of forehead swelling. Percival Pott first described this lesion on 1760. Pott puffy tumor is a rare clinical entity with the advancement in antibiotic treatment. Initially described with head trauma, now it is known to be associated with untreated or partially treated sinusitis; however, cases due to mastoid surgery, dental infections, wrestling injuries, and insect bites have been reported ${ }^{(1-10)}$. Pott puffy tumor can be found in all age groups, but occurs predominantly in adolescents ${ }^{(1-10)}$. Frontal sinuses are often pneumatized by 2 years of age and are approximate adult size by the late teens. Venous drainage occurs through diploic veins that have communication with the dural venous sinuses, which can propagate septic emboli ${ }^{(1-10)}$. Symptoms include headache, periorbital swelling, fever, purulent rhinorrhea, vomiting, and signs of meningitis or encephalitis. Intracranial complications occur due to either direct extension or venous drainage. Complications include meningitis; epidural, subdural, or intra-parenchymal abscess; and cavernous sinus and dural venous sinus thrombosis (1-10). If the inferior wall of the frontal sinus is involved, infection may spread to the orbits, causing either orbital cellulitis or intraorbital abscess ${ }^{(1-12)}$.

Although CT scans have a higher radiation dose, at most centers like ours, MRI scanners are not available around the clock. Particular attention should be paid to decrease the radiation dose by strictly following the pediatric protocols for radiation dose reduction. A CT scan with contrast can be performed if there is a high suspicion of intracranial extension. Intracranial complications with or without direct erosion of the frontal bone have been observed in about $60 \%$ to $85 \%$ of these patients ${ }^{(13-15)}$. Tsai et al. reported a $100 \%$ rate of intracranial complications in their six pediatric patients with Pott puffy tumor ${ }^{(10)}$. Ketenci et al. indicated that intracranial complications are often present during a regimen of antibiotics and are often asymptomatic when the abscess is localized in a silent area of the central nervous system ${ }^{(7)}$. CT scan can demonstrate sinusitis, bone erosion, subperiosteal collection, and intracranial extension. In our case, CT showed frontal sinusitis, bone erosion, subperiosteal collection, and extradural abscess. As with other intracranial pathologies, MRI is the modality of choice ${ }^{(11-17)}$. MRI can better delineate intracranial pathology, dural sinus thrombosis, and bone edema. Abscesses show restricted diffusion on diffusion-weighted sequences, indicating thick viscous pus ${ }^{(1-5)}$. In this case, MRI showed frontal bone edema and extradural abscess, without dural venous sinus or meningeal involvement. MRI is helpful particularly in followup after medical or surgical management, reducing overall radiation exposure. Bone scintigraphy with Tc-mMP may be more sensitive than $\mathrm{CT}$ in detection of early osteomyelitis, but its sensitivity is poor in the setting of acute sinusitis ${ }^{(11-17)}$.

\section{Conclusion}

Early diagnosis and treatment of Pott puffy tumor is necessary. Broad-spectrum antibiotics for 4 to 6 weeks, along with surgical drainage, is the standard of care. This patient underwent functional endoscopic sinus surgery in addition to 4 weeks of antibiotics. Follow-up MRI showed complete resolution.

\section{Authorship contribution}

$\mathrm{KMB}$ designed the concept, was the main surgeon, wrote and revised the manuscript.ZAH and IMI are the senior registrars, received the patient at the OPD, prepared the patient for the surgery, performed postoperative care and follow up, and collected the patient's data.

\section{Acknowledgments}

Not applicable.

\section{Funding}

There was no funding for this report. 
Ethics approval and consent to participate

The patient gave consent for publication to KMB

\section{Availability of data and materials}

Not applicable

\section{Consent for publication}

Not applicable

\section{Conflict of interest}

The authors declare that they have no competing interests.

\section{References}

1. Karaman E, Hacizade $\mathrm{Y}$, Isildak H, Kaytaz A. "Pott's puffy tumor". J Craniofac Surg. 2008, 19 (6): 1694-7.

2. Suwan PT, Mogal S, Chaudhary S. Pott's Puffy Tumor: An Uncommon Clinical Entity. Case Rep Pediatr. 2012; 2012: 386104.

3. Goldberg AN, Oroszlan G, Anderson TD. Complications of frontal sinusitis and their management. Otolaryngol Clin North Am. 2001;34(1):211-225.

4. Tudor RB, Carson JP, Pulliam MW, Hill A. Pott's puffy tumor frontal sinusitis frontal bone osteomyelitis and epidural abscess secondary to a wrestling injury. Am J Sports Med. 1981;9(6):390-391.

5. Raja V, Low C, Sastry A, Moriarty B. Pott's puffy tumor following an insect bite. Postgrad Med. 2007;53(2):114-116.

6. Gupta M, El-Hakim H, Bhargava R, Mehta $\checkmark$. Pott's puffy tumour in a pre-adolescent child: the youngest reported in the post-antibiotic era. Int J Pediatr Otorhinolaryngol. 2004;68(3):373-378

7. Ketenci I, Unlü Y, Tucer B, Vural A. The Pott's puffy tumor: a dangerous sign for intracranial complications. Eur Arch Otorhinolaryngol. 2011;268(12):1755-1763.
8. Nisa L, Landis BN, Giger R. Orbital involvement in Pott's puffy tumor: a systematic review of published cases. Am J Rhinol Allergy. 2012;26(2):e63-e70.

9. Ibarra S, Aguirrebengoa K, Pomposo I, Bereciartúa E, Montejo M, González de Zárate P. [Osteomyelitis of the frontal bone (Pott's puffy tumor). A report of 5 patients.] Enferm Infecc Microbiol Clin. 1999;17(10):489-492.

10. Tsai BY, Lin KL, Lin TY, Chiu CH, Lee WJ, Hsia $\mathrm{SH}$, Wu CT, Wang HS. Pott's puffy tumor in children. Childs Nerv Syst. 2010;26(1):53-60.

11. Verbon A, Husni RN, Gordon SM, Lavertu P, Keys TF. Pott's puffy tumor due to Haemophilus influenzae: case report and review. Clin Infect Dis. 1996;23(6):13051307

12. Reynolds DJ, Kodsi SR, Rubin SE, Rodgers IR. Intracranial infection associated with preseptal and orbital cellulitis in the pediatric patient. J AAPOS. 2003;7(6):413-417

13. Gourineni VC, Juvet $T$, Kumar $Y$, Bordea $D$, Sena KN. Progressive multifocal leukoencephalopathy in a 62-year-old immunocompetent woman. Case Rep Neurol Med. 2014:549271

14. Kumar Y, Hooda K, Li S, Karol I, Muro GJ. A case of spontaneous intracranial hypotension: the role of dynamic CT myelography and epidural blood patch in diagnosis and treatment. Conn Med. 2015;79(9):547-549.

15. Kumar $Y$, Wadhwa V, Phillips L, Pezeshk $P_{1}$ Chhabra A. MR imaging of skeletal muscle signal alterations: systematic approach to evaluation. Eur J Radiol. 2016;85(5):922-935.

16. Kumar $Y$, Khaleel M, Boothe E, Awdeh $H$, Wadhwa V, Chhabra A. Role of diffusion weighted imaging in musculoskeletal infections: current perspectives. Eur Radiol. 2017;27(1):414-423.

17. Uren RF, Howman-Giles R. Pott's puffy tumor: scintigraphic findings. Clin Nucl Med. 1992;17(9):724-727.

Khaled Mohamed Bofares

1 Omar Almoukhtar University

Elbyda

Libya

E-mail: bofaresstat2012@yahoo.com 